\title{
Quantitative analysis of growth stimulation by glycine betaine in Salmonella typhimurium
}

\author{
Su-Pin Koo and Ian R. Booth \\ Author for correspondence: Ian R. Booth. Tel: +44 224 273152. Fax: +44 224273144.
}

Department of Molecular \& Cell Biology, University of Aberdeen, Marischal College, Aberdeen AB9 1AS, UK
The accumulation of compatible solutes, such as glycine betaine, is known to stimulate growth under conditions of osmotic stress. In Salmonella typhimurium the accumulation of glycine betaine is mediated by two osmotically activated transport systems, ProP and ProU. This study was undertaken to determine the quantitative relationship between glycine betaine accumulation from the environment and growth stimulation, and also the relative roles of the high affinity (ProU) and low affinity (ProP) transport systems. Our data show that relatively low concentrations of glycine betaine $(>10 \mu \mathrm{M})$ are sufficient to stimulate growth and that under these conditions ProP and ProU transport systems are equivalent. At external concentrations of glycine betaine below $1 \mu \mathrm{M}$, cells able to express the ProU transport system possess a significant advantage over cells that only possess ProP. At high osmolarity the correlation between growth stimulation and cytoplasmic glycine betaine concentration is limited. At low glycine betaine concentrations further accumulation of the compatible solute stimulated growth. However, once the cells had accumulated $100 \mathrm{nmol}$ glycine betaine per $O D_{650}$ unit biomass no greater growth stimulation was observed in cells with higher levels of the compatible solute. The implications of these data for growth and pathogenicity of bacteria in natural ecosystems, such as foods, are discussed.

Keywords: Osmoregulation, glycine betaine, Salmonella typhimurium, ProP, ProU

\section{INTRODUCTION}

The survival of osmotic stress by a range of bacteria is positively correlated with their ability to accumulate compatible solutes (Imhoff, 1986). These solutes serve two major functions. Firstly, as they are accumulated potassium glutamate is released, and thus their accumulation reduces the ionic strength of the cytoplasm (Booth et al., 1988). Secondly, they are able to exert protection of protein conformation, possibly deriving from their affects on the water structure of the cell (Pollard \& Wyn Jones, 1979; Arakawa \& Timasheff, 1983). Compatible solutes may either be synthesized in the cytoplasm or be transported from the environment. The enteric bacteria synthesize trehalose and some may convert externally supplied choline to glycine betaine (Csonka, 1989). The primary compatible solutes transported from the environment are proline and glycine betaine, although ectoine and taurine have been found to be accumulated under appropriate conditions (Csonka, 1989).

Salmonella typhimurium cannot synthesize glycine betaine, but will accumulate it from the environment (Cairney et al., 1985a, b). Two transport systems, ProP and ProU, have been shown to be the primary routes by which this compatible solute is transported into cells. The former system possesses the lower affinity for glycine betaine, but is expressed constitutively and only undergoes 2- to 3-fold induction during growth at high osmolarity (Cairney et al., 1985a). The ProU system is a high affinity transport system, induced under conditions of osmotic stress and repressed by the accumulation of compatible solutes such as proline and glycine betaine (Cairney et al., 1985b).

Most studies of osmoprotection have been undertaken with millimolar levels of glycine betaine in the medium. However, such high concentrations are unlikely to be found in natural environments or in food. The latter is particularly important since Salmonella typhimurium is a potential pathogen. Similarly, little attention has been paid to the relationship between the intracellular concentration of glycine betaine and the growth stimulation observed. The current study was undertaken to place osmoprotection on a more quantitative footing. We demonstrate that relatively low levels of glycine betaine are sufficient to confer significant osmoprotection and 
that at different osmolarities there is a cytoplasmic concentration above which no further protection is afforded. Further, the limitation on the osmoprotective effects of glycine betaine is not the intracellular concentration of this compound, but must be ascribed to other effects of osmotic stress. At very low cell densities, such as those expected to pertain in foods, as little as $100 \mathrm{nM}$ glycine betaine can be sufficient to exert osmoprotection and this protection is only available to cells expressing the ProU high affinity transport system.

\section{METHODS}

Bacterial strains. The strains used in this study were: $S$. typhimurium $\mathrm{CH} 992 \quad$ (galE503 bio-561 $\Delta$ putP $A 230$ proU1697:: Tn10); S. typhimurium CH638 (galE503 $\Delta$ putP $A 230$ proP1667:: Tn5); S. typhimurium CH627 (galE503 $\Delta$ putP A230) (Cairney et al., 1985a, b).

Media for growth and transport studies. The medium LOM (Cairney et al., 1985a) was used routinely. Glucose $(0 \cdot 2 \%, \mathrm{w} / \mathrm{v}$ ) was used as the carbon and energy source and growth media were supplemented with biotin $\left(10 \mu \mathrm{g} \mathrm{ml}^{-1}\right)$. The medium was supplemented with $\mathrm{NaCl}$ or glucose to raise the osmotic pressure.

Growth protocols. Growth of cells was at $37^{\circ} \mathrm{C}$ in Erlenmeyer flasks with a medium: flask volume ratio of approximately 0.2 to ensure good aeration. The flasks were incubated on a gyratory incubator at 250 r.p.m. Overnight cultures were subcultured into fresh medium to an approximate $\mathrm{OD}_{650}$ of 0.05 (measured in LOM medium) and growth monitored over the next 8-10 h. Viable counts were conducted by serial dilution of growing cultures into LOM medium and spreading $100 \mu \mathrm{l}$ of each dilution onto LK plates (Koo et al., 1991). After overnight growth at $37^{\circ} \mathrm{C}$, the number of colonies on each plate were counted.

Transport protocols. Transport experiments were carried out essentially as described previously (Cairney et al., 1985a; Koo et al., 1991) using cells harvested and washed in LOM medium and stored on ice in the presence of chloramphenicol $\left(12 \cdot 5 \mu \mathrm{g} \mathrm{ml}^{-1}\right)$. All optical density measurements were made on cells incubated in LOM. Radioactive glycine betaine $\left(\left[\mathrm{N}^{14} \mathrm{CH}_{3}\right]\right.$ glycine betaine; stock $55 \mu \mathrm{Ci}(2.035 \mathrm{MBq}) \mu \mathrm{mol}^{-1}$; from ICN) was added from stock solutions approximately 100 -fold more concentrated than that required in the incubation. The specific activity of the glycine betaine was varied by mixing with unlabelled glycine betaine.

\section{Measurement of glycine betaine accumulation during} growth. To determine glycine betaine accumulation during growth, cultures were established as described previously (Koo et al., 1991) and incubated with glycine betaine $(10-800 \mu \mathrm{M})$. Once exponential growth was established $\left(\mathrm{OD}_{650}=0 \cdot 2\right)$, aliquots of culture $(2.5 \mathrm{ml})$ were transferred to wide test-tubes $(2.5 \mathrm{~cm}$ diameter) containing $10-20 \mathrm{nCi}(370-740 \mathrm{~Bq})$ of radioactive glycine betaine and the incubation continued. When growth in the control flask had reached $\mathrm{OD}_{650}=0.4$, the tube was removed from the incubator and the following manipulations undertaken: the $\mathrm{OD}_{650}$ of the culture in the tube was measured; three $0.5 \mathrm{ml}$ samples were taken, filtered through glassfibre filters and washed with $3 \mathrm{ml}$ of growth medium of the same osmotic strength, but lacking glycine betaine. The filters were then dried and the radioactivity trapped in the cells determined by liquid scintillation counting; $50 \mu \mathrm{l}$ samples were removed and transferred to filters and dried as standards for the determination of the glycine betaine specific activity.

\section{RESULTS AND DISCUSSION}

\section{Glycine betaine stimulation of growth of Salmonella typhimurium}

Growth stimulation by glycine betaine was investigated in a S. typhimurium strain (CH992) that possessed only the ProP transport system. As expected from previous studies, growth was progressively inhibited as the osmotic pressure of the environment was raised and glycine betaine alleviated this inhibition (Fig. 1a). At high osmolarity (LOM $+0.7 \mathrm{M} \mathrm{NaCl}$ ) it was observed that, even in the presence of the compatible solute, severe growth inhibition was still observed. At low osmolarities (up to $\mathrm{LOM}+0.3 \mathrm{M} \mathrm{NaCl}$ ), the growth rate was hardly affected by osmotic stress (Fig. 1a) and glycine betaine accumulation was very low (data not shown). At all osmolarities investigated growth stimulation could be observed with glycine betaine concentrations as low as $10 \mu \mathrm{M}$ and the relationship between specific growth rate and external glycine betaine concentration was a simple rectangular hyperbola (Fig. 1b). Maximum growth stimulation was achieved with $100-200 \mu \mathrm{M}$ glycine betaine at each of the osmolarities investigated (Fig. 1b). This value is lower than previous measurements, which had reported that more than $500 \mu \mathrm{M}$ glycine betaine was required for maximum growth stimulation of $S$. typhimurium (Le Rudulier \& Bouillard, 1983).

Stimulation of growth correlated strongly with the intracellular glycine betaine concentration and was independent of the mechanism of glycine betaine accumulation. Strains of S. typhimurium that possessed ProP alone (CH992), ProU alone (CH638) and both ProP and ProU (CH627) were grown in LOM medium containing $0.5 \mathrm{M}$ $\mathrm{NaCl}$ in the presence of $0-200 \mu \mathrm{M}$ glycine betaine. The steady state exponential growth rate and the internal concentration of glycine betaine were measured (Fig. 2). At low cytoplasmic glycine betaine concentrations (10$100 \mathrm{nmol}$ glycine betaine per $\mathrm{OD}_{650}$ unit biomass) growth was stimulated by further increases in the concentration of the compatible solute. However, although cells possessed the ability to accumulate glycine betaine to higher levels no further growth advantage accrued from the increased cytoplasmic pool of this compatible solute (Fig. 2). The mechanism(s) used to transport glycine betaine did not affect the growth stimulation (Fig. 2) and the cytoplasmic level of glycine betaine was not substantially affected by operation of the different transport systems. These data demonstrate that while glycine betaine accumulation was responsible for growth stimulation there was an upper limit to the growth stimulation that can be achieved. It is known that an increase in the osmolarity of the growth environment leads to immediate activation of potassium uptake followed by stimulation of glutamate accumu- 

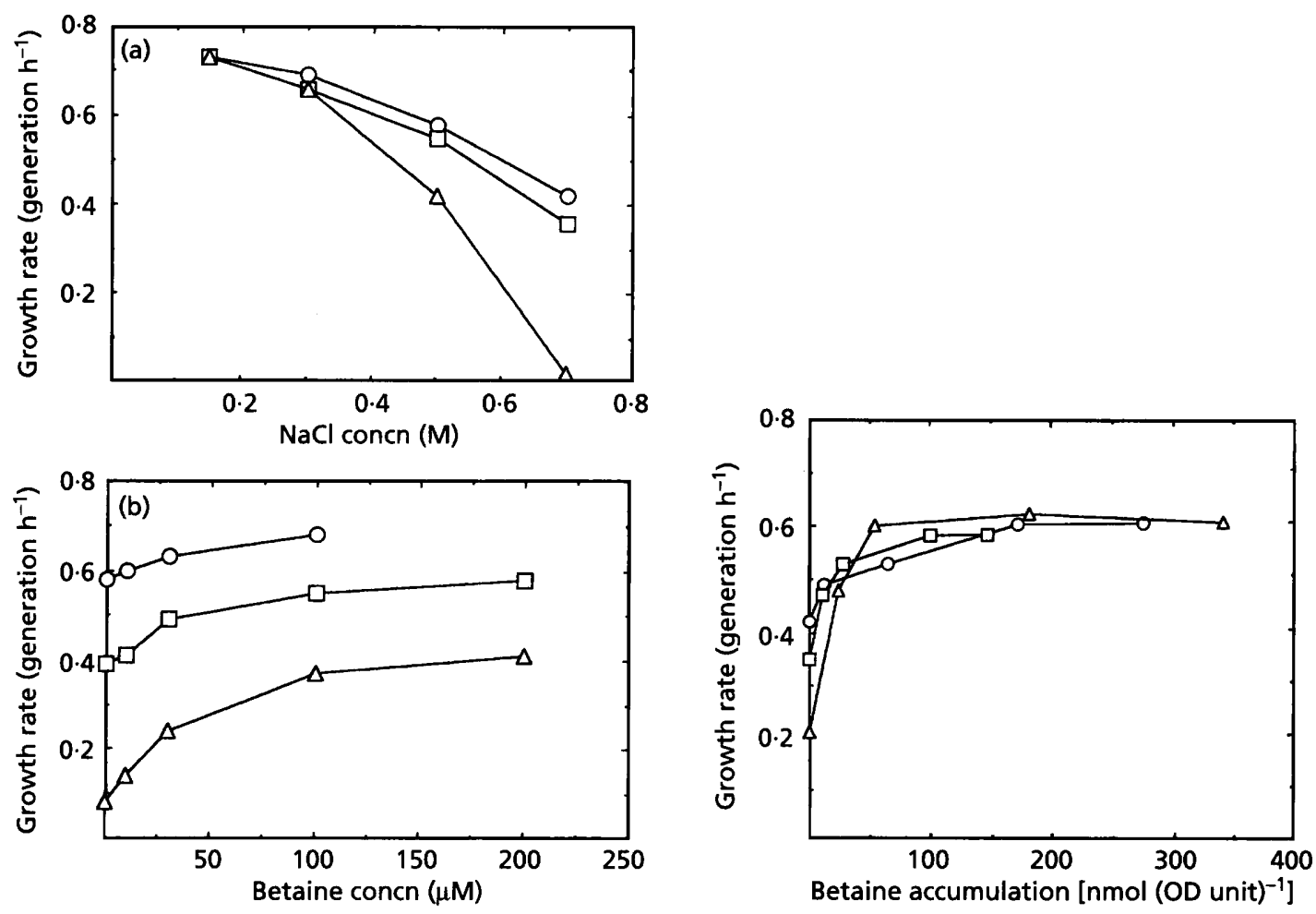

Fig. 1

Fig. 2

Fig. 1. Osmotic protection by betaine. Cells of $S$. typhimurium $\mathrm{CH} 992$ (ProP ${ }^{+}$) were grown overnight in LOM medium with glucose as sole carbon source and were then diluted into LOM containing the indicated concentration of $\mathrm{NaCl}$ and glycine betaine $(0-400 \mu \mathrm{M})$. The cultures were incubated at $37^{\circ} \mathrm{C}$ in a shaking incubator and samples removed at intervals for measurements of $\mathrm{OD}_{650}$. The specific growth rate was calculated from the doubling time of the culture. (a) Growth rate in the absence of glycine betaine $(\triangle)$, and in the presence of $100 \mu \mathrm{M}(O)$ and $400 \mu \mathrm{M}(\square)$ glycine betaine. (b) Influence of glycine betaine concentration on growth rate at three different osmolarities: $L O M+0.3 \mathrm{M} \mathrm{NaCl}(O)$, $+0.5 \mathrm{M} \mathrm{NaCl}(\square)$ and $+0.7 \mathrm{M} \mathrm{NaCl}(\triangle)$. All experimental points are representative of parallel incubations conducted with the same inoculum and have been replicated at least three times.

Fig. 2. Relationship between internal glycine betaine concentration and growth rate. Strains of $S$. typhimurium that possessed ProP alone (CH992; O), ProU alone $(\mathrm{CH} 638 ; \triangle)$ and both ProP and ProU $(\mathrm{CH} 627 ; \square)$ were grown in LOM medium containing $0.5 \mathrm{M} \mathrm{NaCl}$ in the presence of $0-200 \mu \mathrm{M}$ glycine betaine. The measurement of internal glycine betaine was accomplished as described in Methods.

lation (Epstein, 1986). Further, it has been demonstrated both that salts reduce enzyme activity (Pollard \& Wyn Jones, 1977) and that high osmolarity affects the activity of membrane-located enzyme systems (Roth et al., 1984). The accumulation of compatible solutes in the cytoplasm exerts growth stimulation due firstly to the release of potassium from the cytoplasm, thus lowering the ionic strength, and secondly, from affects on water structure such that proteins are preferentially rehydrated (Arakawa \& Timasheff, 1983; Cayley et al., 1992). It follows that while these effects of compatible solutes are beneficial to enzymes in the cytoplasm and consequently lead to growth stimulation, externally facing enzymes and periplasmically located enzymes, which are essential for cell growth, are not similarly protected. Consequently, it is possible that our observations, both of an upper limit of protection afforded by compatible solute accumulation and of the well-established increasing severity of growth inhibition as the osmolarity of the medium is raised (Booth et al., 1988), can be explained by the different levels of protection given to the two compartments of the cell. The membrane and the periplasm are both essential to cell growth but compatible solute accumulation in the cytoplasm affords them little protection.

\section{ProU, but not ProP, can effect osmotic protection at very low glycine betaine concentrations}

When growth is analysed by light scattering there is a requirement for high cell densities. When a nutrient is required in significant amounts, the high cell density poses problems for analysis of growth at low nutrient concentrations. This can be overcome by the use of chemostats, but only at fixed growth rates. To overcome this problem and to allow determination of growth stimulation by very low glycine betaine concentrations, 


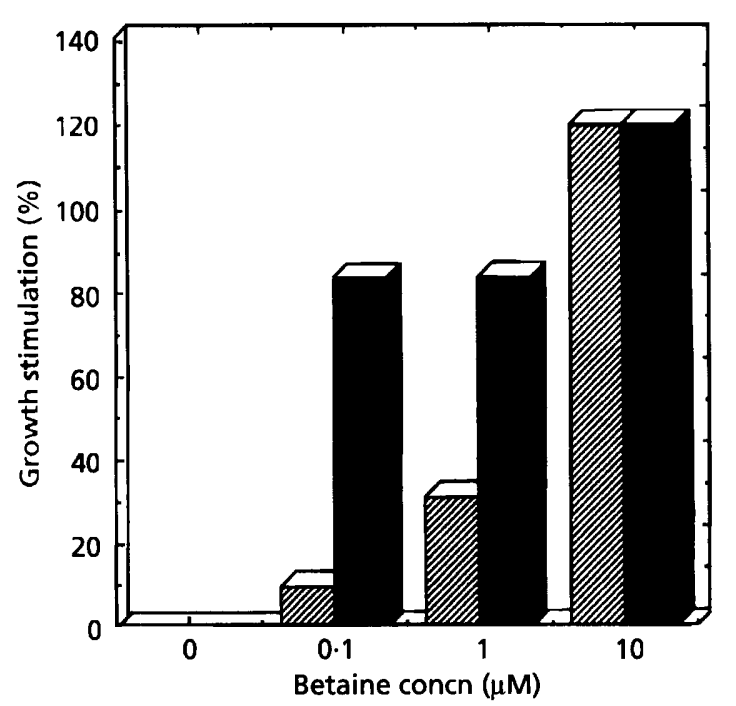

Fig. 3. Growth stimulation by very low glycine betaine

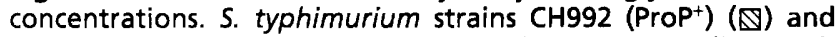
$\mathrm{CH} 638\left(\mathrm{ProU}^{+}\right)(\square)$ were grown overnight in LOM medium with glucose as sole carbon source. Cultures were diluted to give approximately $10^{4}$ organisms (ml culture) $)^{-1}$ in LOM $+0.5 \mathrm{M} \mathrm{NaCl}$. Glycine betaine $(0 \cdot 1-10 \mu \mathrm{M})$ was added to the cultures and the incubation continued as described in Fig. 1. At intervals samples were removed and the viable count was established as described in Methods. The specific growth rate was calculated from the doubling time of the cultures and the growth stimulation was determined by comparison with control cultures that lacked glycine betaine.

we used very dilute cell cultures and assayed growth through the increase in viable plate counts. Strains $\mathrm{CH} 992$ $\left(\mathrm{ProP}^{+}\right.$) and $\mathrm{CH} 638\left(\right.$ ProU $^{+}$) were inoculated at approximately $10^{4}$ cells $\mathrm{ml}^{-1}$ in LOM medium containing $0.5 \mathrm{M}$ $\mathrm{NaCl}$ and glycine betaine in the range $0 \cdot 1-10 \mu \mathrm{M}$ and the growth of the cultures at $37^{\circ} \mathrm{C}$ was followed for several generations. Growth rates were determined and are plotted as the percentage growth stimulation relative to the control which contained no glycine betaine (control growth rates of the two strains were identical and were similar to those shown for $\mathrm{CH} 992$ in Fig. 1a, b). At $100 \mathrm{nM}$ and $1 \mu \mathrm{M}$ glycine betaine, the growth stimulation observed in strain $\mathrm{CH} 638$, which expresses the ProU transport system, greatly exceeded that observed with strain $\mathrm{CH} 992\left(\right.$ ProP $\left.^{+}\right)$(Fig. 3). At higher concentrations of glycine betaine the growth stimulation observed was similar for both strains, which is consistent with data obtained with high density cultures (Fig. 2). Thus, for cells with a high affinity scavenging system (e.g. ProU), only very low concentrations of glycine betaine are required to effect osmoprotection. There are few published data on the levels of glycine betaine in foods but, given the ubiquity of this compatible solute, it is likely that there is sufficient glycine betaine present for the cells to overcome moderately high levels of osmotic stress.

In conclusion, we have shown that over a limited range of internal concentrations there is a linear relationship between growth rate and glycine betaine concentration, but that there is an upper limit to growth stimulation which is probably imposed by the sensitivity to osmotic pressure of structures not protected by compatible solutes. Generally, studies on osmoprotection have been conducted at high glycine betaine concentrations. We have demonstrated in this study that bacterial cells may be protected by levels of glycine betaine as low as $100 \mathrm{nM}$. We have only examined the impact of supplied glycine betaine; many organisms possess the ability to convert choline to glycine betaine and this precursor may be readily available in foods to support osmotic adaptation. It is known that there are multiple choline transport systems in the enteric bacteria (Landfald \& Strøm, 1986; Lamark et al., 1991) and similar considerations may apply to choline as have been identified for glycine betaine. However, S. typhimurium, which lacks the ability to convert choline to glycine betaine, is dependent upon an external supply of this compatible solute. Finally, it is known that high osmolarity is one of the environmental stimuli that elicit the expression of genes involved in determining bacterial pathogenicity. Changes both in DNA topology and in the activity of DNA binding proteins are implicated in control over the expression of these genes. It is believed that the same mechanisms that control the expression of enzyme systems involved in compatible solute synthesis and transport operate for the control by osmolarity of pathogenicity genes (Dorman, 1991; Dorman \& Ni Bhriain, 1993). Since it is known that the accumulation of glycine betaine reverses the osmotic induction of many genes (Booth \& Higgins, 1991) a simple consideration when considering the pathogenicity of bacteria found in foods will be the availability of trace levels of compatible solutes. The studies reported here show that at the low cell densities typical of food contamination $100 \mathrm{nM}$ glycine betaine is sufficient to restore the growth of $S$. typhimurium and consequently, may be effective in reducing the expression of pathogenicity determinants.

\section{ACKNOWLEDGEMENTS}

This work was supported by a grant from the AFRC (FG1/560).

\section{REFERENCES}

Arakawa, T. \& Timasheff, S. N. (1983). Preferential interactions of proteins with solvent components in aqueous amino acid solutions. Arch Biochem Biopbys 224, 169-177.

Booth, I. R. \& Higgins, C. F. (1990). Enteric bacteria and osmotic stress: intracellular potassium glutamate as a secondary signal of osmotic stress? FEMS Microbiol Rev 75, 239-246.

Booth, I. R., Cairney, J., Sutherland, L. \& Higgins, C. F. (1988). Enteric bacteria and osmotic stress: an integrated homeostatic system. J Appl Bacteriol Symp Suppl 35S-49S.

Cairney, J., Booth, I. R. \& Higgins, C. F. (1985a). Salmonella typhimurium proP gene encodes a transport system for the osmoprotectant glycine betaine. J Bacteriol 164, 1218-1223.

Cairney, J., Booth, I. R. \& Higgins, C. F. (1985b). Osmoregulation of gene expression in Salmonella typhimurium: proU encodes an osmotically-induced glycine betaine transport system. J Bacteriol 164 , 1224-1232. 
Cayley, S., Lewis, B. A. \& Record, T., Jr (1992). Origins of the osmoprotective properties of betaine and proline in Escherichia coli K-12. J Bacteriol 174, 1585-1595.

Csonka, L. N. (1989). Physiological and genetics responses of bacteria to osmotic stress. Microbiol Rev 53, 121-147.

Dorman, C. J. (1991). DNA supercoiling and environmental regulation of gene expression in pathogenic bacteria. Infect Immun 59, 745-749.

Dorman, C. J. \& Nf Bhriain, N. (1993). DNA topology and bacterial virulence gene regulation. Trends Microbiol 1, 92-99.

Epstein, W. (1986). Osmoregulation of potassium transport in Escherichia coli. FEMS Microbiol Rev 39, 73-78.

Faatz, E., Middendorf, A. \& Bremer, E. (1988). Cloned structural genes for the osmotically regulated binding-protein-dependent glycine betaine transport system (ProU) of Escherichia coli K-12. Mol Microbiol 2, 265-279.

Imhoff, J. F. (1986). Osmoregulation and compatible solutes in eubacteria. FEMS Microbiol Rev 39, 57-66.

Koo, S.P., Higgins, C. F. \& Booth, I. R. (1991). Regulation of compatible solute accumulation in Salmonella typhimurium: evidence for a glycine betaine efflux system. J Gen Microbiol 137, 2617-2625.
Lamark, T., Kaasen, I., Eschoo, M. W., Falkenberg, P., McDougall, J. \& Strøm, A. R. (1991). DNA sequence and analysis of the bet genes encoding the osmoregulatory choline-glycine betaine pathway of Escherichia coli. Mol Microbiol 5, 1049-1064.

Landfald, B. \& Strøm, A. R. (1986). Choline-glycine betaine pathway confers a high level of osmotic tolerance in Eschericbia coli. $J$ Bacteriol 165, 849-855.

Le Rudulier, D. \& Bouillard, L. (1983). Glycine betaine, an osmotic effector in Klebsiella pneumoniae and other members of the Enterobacteriaceae. Appl Environ Microbiol 46, 152-159.

Perroud, B. \& Le Rudulier, D. (1985). Glycine betaine transport in Eschericbia coli: osmotic modulation. J Bacteriol 161, 393-401.

Pollard, A. \& Wyn Jones, R. G. (1979). Enzyme activities in concentrated solutions of glycine betaine and other solutes. Planta 144, 291-298.

Roth, W. G., Leckie, M. P. \& Dietzler, D. N. (1984). Osmotic stress drastically inhibits active transport of carbohydrates by Escherichia coli. Biocbem Biopbys Res Commun 126, 442-449.

Received 1 June 1993; revised 25 August 1993; accepted 11 October 1993. 